\title{
Electric Field Breakdown of Polymer Based Nano-Composite at Room and Cryogenic Temperatures
}

\author{
H.Rodrigo ${ }^{1, a}$, G.H.Heller ${ }^{1, b}$, A.Ingrole ${ }^{2, \mathrm{c}}, \mathrm{Z}$ (Richard) Liang $^{2, \mathrm{~d}}$, D.G.Crook ${ }^{1, \mathrm{e}}$, \\ and S.L.Ranner ${ }^{1, f}$ \\ ${ }^{1}$ Center for Advanced Power Systems, Florida State University, Tallahassee, FL, USA. \\ ${ }^{2}$ Department of Industrial and Manufacturing Engineering, FAMU-FSU College of Engineering, \\ Tallahassee, FL, USA. \\ arodrigo@caps.fsu.edu, bheller@caps.fsu.edu, caniket.ingrole@gmail.com, liang@eng.fsu.edu, \\ ecrook@caps.fsu.edu, rranner@caps.fsu.edu
}

Keywords: Nanodielectrics, cryogenic dielectrics, DC breakdown, Polymethylmethylacrylate (PMMA), Barium Titanate (BTA).

\begin{abstract}
Electrical breakdown field measurements on Polymethylmethylacrylate (PMMA) and a nano-composite of PMMA/Barium Titanate (BTA) by 10\% wt are presented. The measurements were made using uniform field electrode configuration under high voltage DC. The electrodes were made of stainless steel, each having a Bruce profile, and diameter $25 \mathrm{~mm}$. The measurements were made at room temperature $(293 \mathrm{~K})$ and liquid Nitrogen temperature $(77 \mathrm{~K})$. Using Weibull statistics it shows that both PMMA and the nano-composite have breakdown electrical field strengths much higher at $293 \mathrm{~K}$ than at $77 \mathrm{~K}$. It has been shown that there was very marked improvement in the reliability of results for both compounds at $77 \mathrm{~K}$ over those at $293 \mathrm{~K}$. The SEM micrographs have shown very distinct differences in the behavior of the nano-compound between $293 \mathrm{~K}$ and $77 \mathrm{~K}$, PMMA also exhibit some clear differences.
\end{abstract}

\section{Introduction}

The rapid progress on HTS power applications has boosted research on cryogenic dielectrics, as they require tailored insulation for each purpose. Research into nanotechnology has grown exponentially over the last decade. The development of nanocomposites represents a very attractive route to upgrade and diversify properties of "old" polymers without changing polymer compositions and processing [1-2]. Results obtained from researchers on nanometric dielectrics have shown some improvement in the breakdown characteristics, when compared with base polymers, [3-7]. Preliminary results have shown that the nanocomposites made from PMMA (Polymethyl Methacrylate) and BTA (Barium Titanate) $5 \%$ by weight have the same or slightly better breakdown characteristics as that of neat PMMA. PMMA was selected because it has better electrical properties at cryogenic temperature [8]. The nanocomposites were tested for AC and Impulse breakdown at room and cryogenic temperature [9]. In this paper we present our investigations on nanocomposites with BTA $10 \%$ by weight in base polymer PMMA. The materials were manufactured by Anti solvent Precipitation method (ASP) which gives good dispersion of 
nanoparticles in the matrix. The characterizations were carried out for DC voltages at room and cryogenic temperatures.

\section{EXPERIMENTAL ARRANGEMENT AND PROCEDURE}

\section{Sample Preparation}

Fig. 1 shows a flow chart for fabrication of samples. Brief descriptions are given for methods used for neat PMMA and PMMA/BTA (10\% wt).

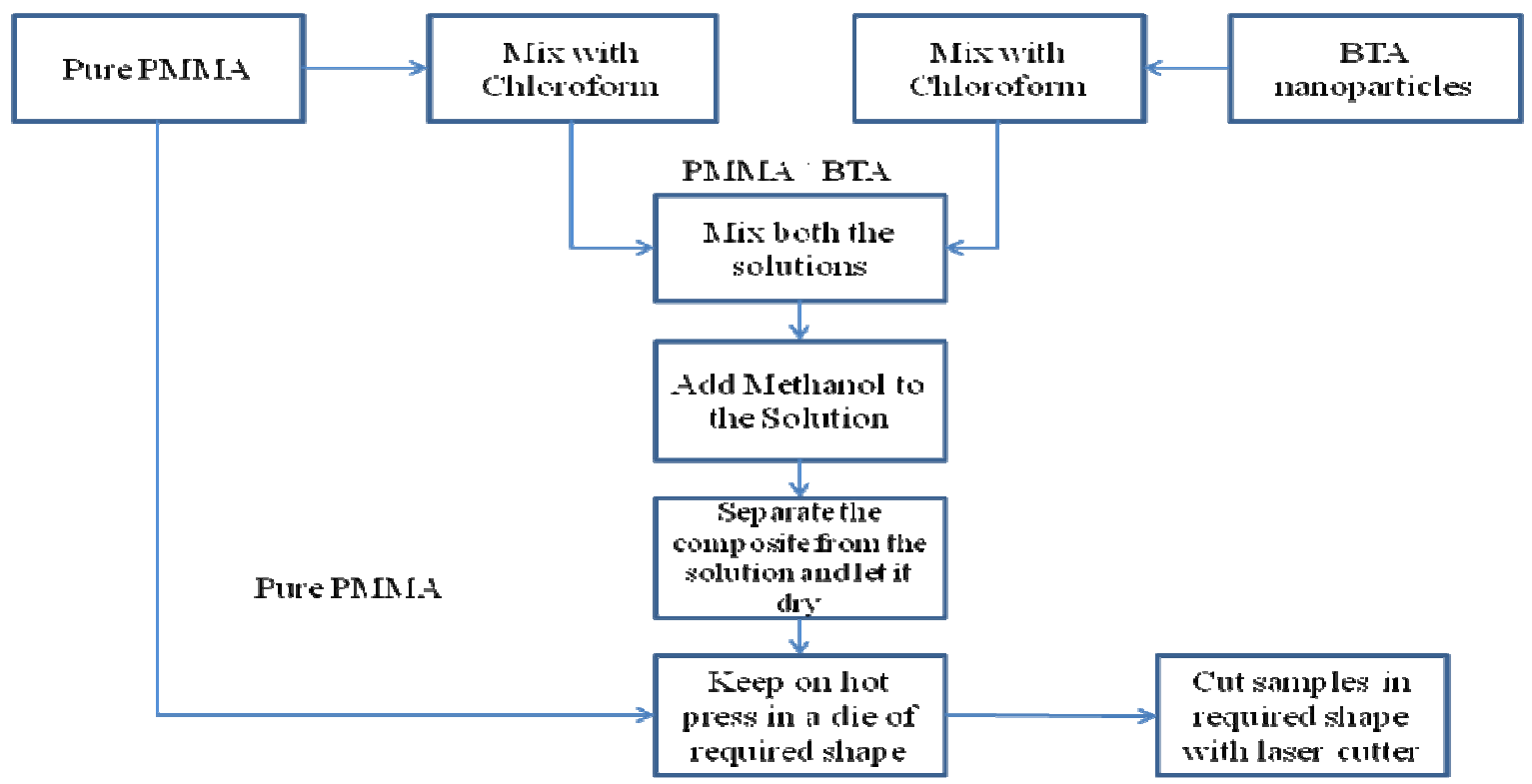

Figure 1: Fabrication process for PMMA and PMMA/BTA samples

Pure PMMA: Neat PMMA (Polymethylmethacrylate) was weighed and placed on a hot die press; the temperature was raised gradually until the temperature reached $220^{\circ} \mathrm{C}$. Pressure was then applied on the press (4.5 Ton). The pressure was maintained and the sample was allowed to cool for between 7 and 10 hours. The clear sheet of PMMA whose thickness was approximately $0.1 \mathrm{~mm}$ was then removed from the press and cut using a laser cutter to the required size.

PMMA/BTA (10\% by wt.): A novel method was used to manufacture nanocomposites, which has the promise to give good dispersion of nanoparticles in the matrix. The method is known as Anti solvent Precipitation (ASP), in which an agglomerate of the polymer and nanoparticles were precipitated from the solvent. 13.5 g of PMMA crystals were dissolved in $150 \mathrm{ml}$ of Chloroform. $1.5 \mathrm{~g}$ of BTA was mixed with $600 \mathrm{ml}$ of Chloroform on sonicator for 2 hours. The two solutions were mixed and left on a sonicator for a further 20 minutes. The resulting solution was then mixed with about 1.5 liters of methanol. The solution was continuously stirred with a mechanical stirrer to enable co- precipitation of PMMA and the nanoparticles. The solids were filtered from methanol and were allowed to dry for between 10 and 12 hours in a vacuum oven. The semi-solid was then placed on a hot press and the temperature was gradually raised until it reached $220^{\circ} \mathrm{C}$, a pressure of 
4.5 Tons was then applied to the sample. The press was allowed to cool for between 7 and 10 hours. The resulting sheet (thickness $\sim 0.1 \mathrm{~mm}$ ) of PMMA/BTA was then removed and cut to required size using a laser cutter.

\section{Laboratory Procedure:}

There were two experiments performed for each sample material: DC breakdown at $293 \mathrm{~K}$ and 77 K. For each test, the samples were cleaned with isopropyl alcohol and the thicknesses measured with Vernier calipers.

\section{Experimental Setup:}

For the room temperature measurements, two $25 \mathrm{~mm}$ diameter Bruce Profile electrodes were cleaned with alcohol. One electrode was inserted into an acrylic cup and then attached to the steel rod at the bottom of the G10 sample holder. The other electrode was attached onto a stainless steel rod inserted at the top of the sample holder. The sample material was placed on the bottom electrode and the top electrode was lowered onto the sample. The stainless steel rod was then locked into place with a G10 bolt at the top of the sample holder. The ground connection was attached to the steel extending out of the side of the bottom of the sample holder, and the cup was filled with silicon transformer oil. The entire setup was placed on a G10 platform in a splash container, and connected to the DC generator. Fig. 2 shows a schematic of the experimental set up.

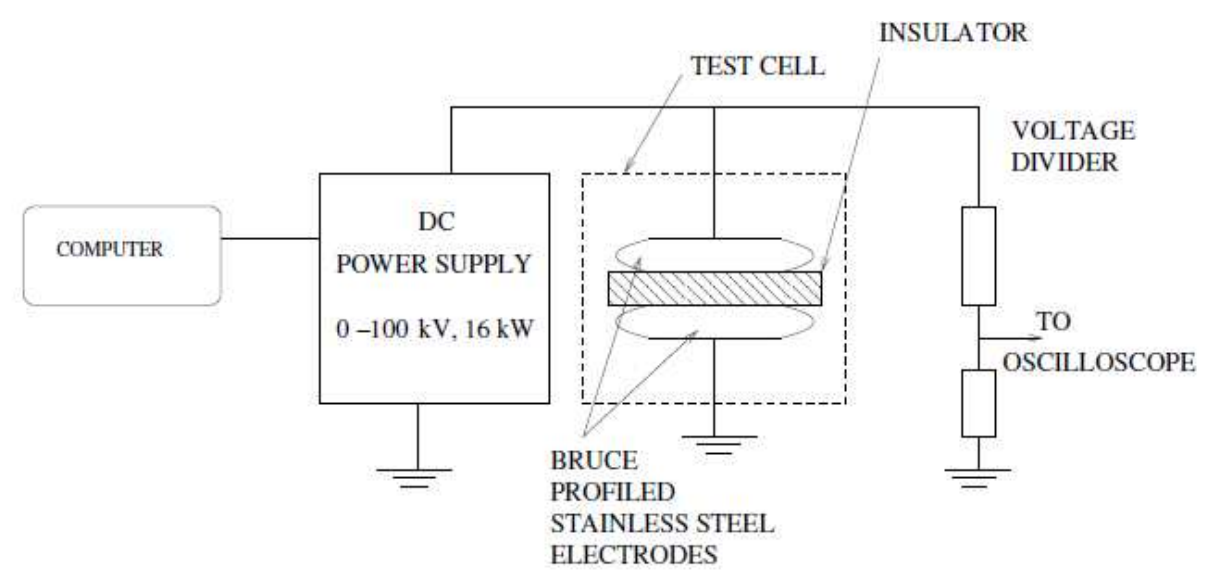

Figure 2: Schematic of the experimental procedure for DC measurements.

For tests performed in liquid nitrogen, the lower electrode was attached to the sample holder without the acrylic cup. The stainless steel rod was not locked in place immediately, but was instead held pressing down onto the sample with a welding clamp, and the ground connection was attached to the steel rod at the bottom of the sample holder. The entire assembly was immersed in a bath of liquid nitrogen. After the temperature equalized, the stainless steel rod was locked into place with the G10 bolt and the welding clamp was removed. Care being taken that the pressure exerted on the sample was always the same for each sample under test. 


\section{Breakdown Measurements}

The electrode assembly with the sample was connected to a DC power supply, rated at $100 \mathrm{kV}, 16$ kW (Glassman Model SH100R160). The power supply was controlled using a computer programmed by LabView (version 8.2). The voltage was ramped at 500 volts per second until a breakdown occurred. The breakdown voltage and waveform were recorded. The samples used were approximately $0.15 \mathrm{~mm}$ thick, and fifteen samples were tested at each temperature.

\section{Results:}

The threshold field value, $(\mathrm{E})_{63.2 \%}$, given in table 1 is where each line of probability crosses the dashed horizontal line on the plot above. If neat PMMA is used as a base line, then the threshold value of neat PMMA at $77 \mathrm{~K}$ is $45.5 \%$ of that at the room temperature. Similarly, the threshold values of PMMA/BTA (10\% wt.) are $84.6 \%$ and $64.9 \%$, for the $293 \mathrm{~K}$ and $77 \mathrm{~K}$ measurements, respectively, of the room temperature neat PMMA measurements.

The slope of each line, $\beta$ (shape factor), in the table is representative of how reliable the data is. It is represented by the steepness of the slope of the fit line on the probability chart. More reliable results are represented by steeper slopes. Using neat PMMA as the base line, neat PMMA at $77 \mathrm{~K}$ has improved by a factor of 3.56. Similarly the slopes for PMMA/BTA (10\% wt.) at $293 \mathrm{~K}$ and 77 $\mathrm{K}$ have improved by a factor of 3.21 and 5.65 respectively.

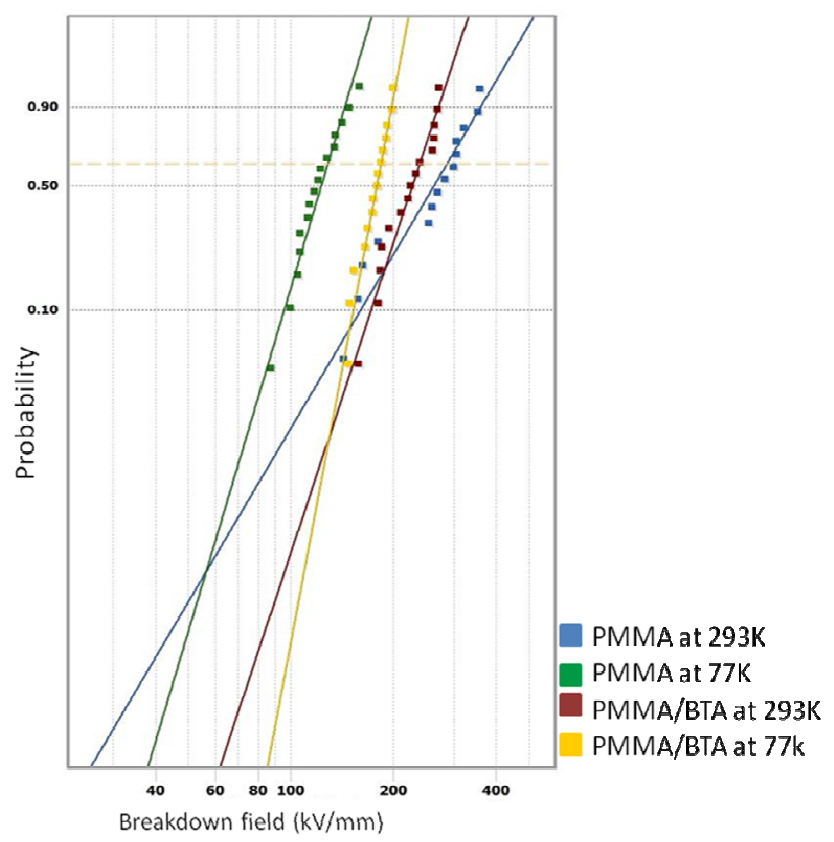

\begin{tabular}{|c|c|c|c|c|}
\hline & \multicolumn{2}{|l|}{$\mathrm{E}_{63.2 \%}(\mathbf{k V} / \mathbf{m m})$} & \multicolumn{2}{|c|}{$\boldsymbol{\beta}$} \\
\hline & $293 \mathrm{~K}$ & $77 \mathrm{~K}$ & $293 \mathrm{~K}$ & $77 \mathrm{~K}$ \\
\hline PMMA Neat & 282.15 & 128.39 & 2.12 & 7.55 \\
\hline $\begin{array}{c}\text { PMMA/BTA } \\
\text { (10\%wt.) }\end{array}$ & 238.73 & 183.06 & 6.8 & 11.97 \\
\hline
\end{tabular}

Table1: Threshold field values \& shape factors values.

Figure 3: Weibull probability plots for neat PMMA at 293K \& $77 \mathrm{~K}$ and PMMA with $10 \%$ by weight BTA at $293 \mathrm{~K} \& 77 \mathrm{~K}$. 


\section{Fracture Surface Analysis}

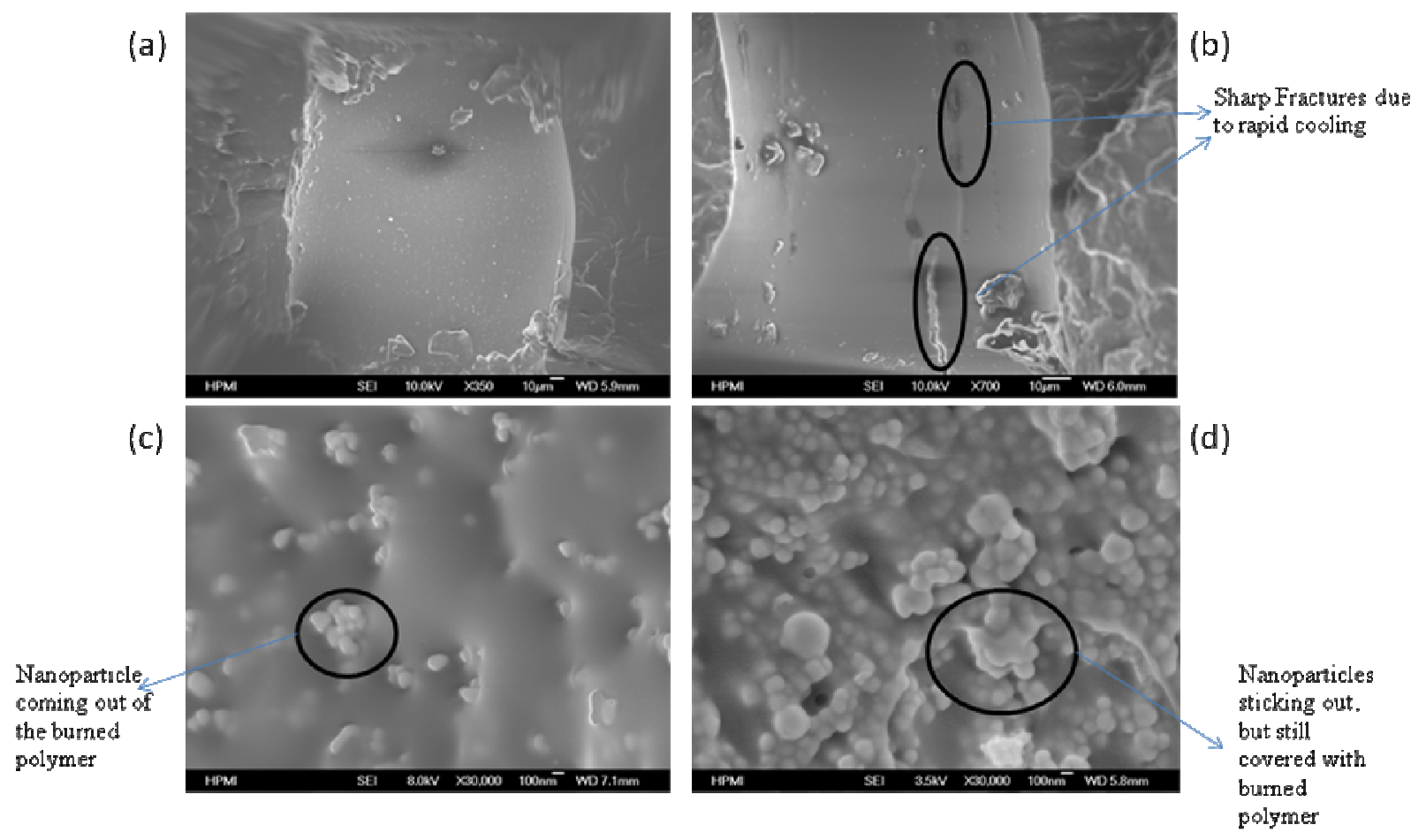

Figure 4: Breakdown area of PMMA (a) at $293 \mathrm{~K}$, (b) at 77K \& of PMMA/BTA (10\% by wt) (c) at $293 \mathrm{~K},(\mathrm{~d})$ at $77 \mathrm{~K}$

Fig. 4 shows the DC breakdown area of the base polymer (PMMA) at 293K and 77K. The SEM images show that the damage to the dielectric was similar at both temperatures except for the cracks formed on the surface of the sample at $77 \mathrm{~K}$. When the voltage was applied and the breakdown occurred, the polymer in that region was burned in each case. But at cryogenic temperature, because of the very low temperature around it, the material was rapidly quenched. Due to this rapid quenching of the material, there were cracks formed at the breakdown area. Similar cracks were also observed for the fabricated nanocomposites, after breakdown occurred at $77 \mathrm{~K}$. In the case at $293 \mathrm{~K}$, the experiment was carried out in a bath of transformer oil. After the breakdown of the material (PMMA/BTA), it took a longer time for the melted polymer to cool. During that period the nano-particles migrated out of the bulk material sticking out of the surface. Due to surface tension, brought about by the fact that the surface area of the nano-particles being larger, thus resulting in cluster formation. These clusters were not formed at $77 \mathrm{~K}$, due to the fact that after melting there was very rapid cooling of the material which trapped the nano-particles. As shown in Fig. 4(d), the nano-particles are on the surface of the polymer in the form of clusters, covered by the host polymer PMMA. 


\section{Acknowledgements}

Research conducted under DoE contract number D-FC26-07NT43221 and ONR/ESRDC contract number N00014-08-1-0080. Thanks are also due to the High-Performance Material Institute (HPMI) at Florida State University.

\section{References:}

1. D. R. James, I. Sauers, M. O. Pace, and A. R. Ellis, IEEE Dielectrics and Electrical Insulation Society, pp. 542 (2002).

2. E. Tuncer, I. Sauers, D. R. James, A. R. Ellis, M. P. Paranthaman, T.Aytug, S. Sathyamurthy, K. L. More, J. Li, and A.Goyal, Nanotechnology, Vol. 18, p. 025703, (2007).

3. J. K. Nelson and Y. Hu, J. Phys. D: Appl. Phys., Vol. 38, pp. 213 (2005).

4. Y. Cao, P. C. Irwin, and K. Younsi, IEEE Trans. Dielect. Electr. Insul., Vol. 11, pp. 797 ( 2004).

5. M. F. Frechette, M. L. Trudeau, H. D. Alamdari, and S. Boily, IEEE Trans. Dielect. Electr. Insul., Vol. 11, pp. 808 (2004).

6. J. K. Nelson and J. C. Fothergill, Nanotechnology, Vol. 15, pp. 586 (2004).

7. E. Tuncer, I. Sauers, D. R. James, A. R. Ellis, M. P. Paranthaman, A. Goyal, and K. L. More, Nanotechnology, Vol.18, pp.325704, (2007).

8. Kosaki, M., IEEE Electrical Insulation Magazine, 12(5): p. 17-24 (1996).

9. H.Rodrigo, W.Baumgartinger, A.Ingrole, Z (Richard) Liang, D.G.Crook and S.L.Ranner, Proceedings of Materials Research Society, Symposium BB paper number BB3.10 (2009). 